\title{
Neutrophil-to-Lymphocyte Ratio as a Marker in Patients with Non-arteritic Anterior Ischemic Optic Neuropathy
}

\author{
Onur Polat, Güliz Fatma Yavaş, Sibel İnan, Ümit Übeyt İnan \\ Department of Ophthalmology, Afyon Kocatepe University Faculty of Medicine, Afyonkarahisar, Turkey
}

Background: Non-arteritic anterior ischemic optic neuropathy (NAION) is the most common acute optic neuropathy in patients over the age of 50 and is the second most common cause of permanent optic nerverelated visual loss in adults after glaucoma. Although the precise cause of NAION remains elusive, the etiology of NAION is believed to be multifactorial.

Aims: To evaluate the utility of neutrophil-to-lymphocyte ratio (NLR) as a simple and readily available prognostic factor for clinical disease activity in patients with NAION.

Study Design: Case-control study.

Methods: Forty-five patients with the diagnosis of NAION and 50 age- and sex-matched controls with/ without any systemic or ocular diseases except cataract were retrospectively enrolled in the study. Demographic characteristics and laboratory findings including complete blood count of all patients and control subjects were obtained from the electronic medical record.
The neutrophil and lymphocyte counts were recorded and the NLR was calculated.

Results: White blood cell, neutrophil, NLR and platelet values of the NAION patients were significantly higher than those of the controls $(\mathrm{p}<0.001, \mathrm{p}<0.001, \mathrm{p}=0.004$, $\mathrm{p}=0.037$, respectively). Initial NLR values were negatively correlated with initial and the third month best corrected visual acuity levels in the study group. The optimum NLR cut-off point for NAION was 1.94.

Conclusion: NLR could be considered as a new inflammatory marker for assessment of the severity of inflammation in NAION patients with its quick, cheap, easily measurable property with routine complete blood count analysis.

Keywords: Disease severity, marker, neutrophil-tolymphocyte ratio, non-arteritic anterior ischemic optic neuropathy
Non-arteritic anterior ischemic optic neuropathy (NAION) is one of the most common causes of sudden, painless and permanent vision loss in the middle-aged and elderly population. The pathogenesis of this condition is unknown but acute ischemia of the optic nerve head is generally accepted in the pathogenesis of NAION $(1,2)$. Systemic diseases such as diabetes mellitus (DM), hypertension, nocturnal arterial hypotension, ischemic heart disease, cerebrovascular events and atherosclerosis constitute the main risk factors for circulatory insufficiency. Also, some mechanical and genetic factors such as the small size of the optic nerve head may predispose the development of NAION. Therefore, NAION is a multifactorial disease and many risk factors play roles in its development (3-5).

White blood cells (WBC) and its subtypes are used as inflammatory markers in a variety of inflammatory conditions, in particular cardiovascular disorders. It has been shown that increased neutrophil count is related to areas of ischemic injury (6-8). Furthermore, there are studies showing that there is a chronic low grade inflammation in DM (9), hypertension (10), metabolic syndrome (11), and obesity (12). 
The neutrophil-to-lymphocyte ratio (NLR) was found to be a useful inflammatory marker with other inflammatory markers in various diseases (13-15). Neutrophil-mediated cellular inflammation has been shown to play a role in the early period of NAION $(16,17)$.

To the best of our knowledge, NLR values have not been previously investigated in NAION. This retrospective study was conducted to assess the relationship between NAION and inflammation by using NLR and to investigate whether NLR can be used as a prognostic factor in NAION.

\section{MATERIALS AND METHODS}

The current study included 45 patients diagnosed with NAION between April 2008 and October 2013 and 50 ageand gender-matched patients in the control group with/without any systemic disease and from whom a complete blood count (CBC) was obtained during routine preoperative laboratory examination for cataract surgery. Subjects with NAION were subdivided into two groups: 1 . subjects without any systemic disease, and 2. subjects with DM and/or hypertension. The control group was similarly subdivided into two groups: 1 . subjects without any systemic disease, and 2. subjects with $\mathrm{DM}$ and/or hypertension without any finding of retinopathy. Baseline characteristics of all patients obtained from the electronic medical record included age, gender, ocular findings, systemic diseases and drug history and laboratory findings. The institutional review board approved the study.

Diagnosis of NAION was made in patients who presented with sudden vision loss after ocular, fundoscopic and laboratory examination. Best corrected visual acuity (BCVA) measured by Snellen chart at the initial examination was recorded. The patients were classified into four groups according to initial BCVA levels. Patients with BCVA less than 0.03 composed Group 1, between 0.05 and 0.1 formed Group 2, between 0.2 and 0.4 composed Group 3 and $\geq 0.5$ composed Group 4. Normal ocular examination had been performed. Visual field testing was performed by Humphrey field analyzer with a full-threshold strategy of 30-2, and optic disc scanning using the optical coherence tomography and laboratory testing were carried out to support the diagnosis. Diagnostic criteria for NAION were the presence of sudden and painless visual loss, complete or incomplete optic disk edema, altitudinal defect in visual field test and normal serum erythrocyte sedimentation rate (ESR) and C-reactive protein (CRP) levels. Differentiation from giant cell arteritis was achieved due to normal levels of ESR and CRP, and the absence of complaints such as weight loss, temporal artery tenderness, and jaw claudication. Biopsy of the temporal artery was only performed if giant cell arteritis was suspected (18). Visual acuity at the third month was also recorded.

Patients were excluded from the study in the presence of chronic heart or liver disease, coronary artery disease, or a history of malignancy. Subjects using anticoagulant or antiplatelet agents, subjects in whom initial laboratory testing had not been performed within the 10 days following visual loss were excluded from the study. Additionally, patients with ocular pathologies like corneal scarring, retinal diseases, cataract or amblyopia that could affect BCVA were not included in the study.

\section{Biochemical and hematological analyses}

In our clinic, CBC, ESR, CRP, level of fasting glucose, liver and renal function tests and lipid profile are routinely evaluated in subjects with the suspect of NAION. Blood samples were taken at the time of NAION diagnosis and drawn into vacutainer tubes containing dipotassium ethylenediaminetetraacetic acid (EDTA). The hematological measurements were obtained by using an automated blood cell counter (BeckmanCoulter LH 780 Analyzer, Miami, Florida, USA). WBC, neutrophil, lymphocyte, monocyte, hemoglobin, platelet, and NLR levels were recorded. The following reference values were determined: for WBC: $4-10 \times 10^{3} / \mathrm{mm}^{3}$, neutrophil: $1.5-$ $7 \times 10^{3} / \mathrm{mm}^{3}$, lymphocyte: $1-3.7 \times 10^{3} / \mathrm{mm}^{3}$, monocyte: $0-0.7$ $\mathrm{x} 10^{3} / \mathrm{mm}^{3}$, hemoglobin: $12-17 \mathrm{~g} / \mathrm{dL}$, and platelet: $160-450 \mathrm{x}$ $10^{3} / \mathrm{mm}^{3}$.

\section{Statistical analysis}

SPSS (Statistical Package for Social Sciences Inc., Chicago, IL, USA) 18.0 program was used for statistical analysis. Continuous variables were presented as mean \pm SD values and categorical variables were expressed as percentage. Data comparison was performed with independent sample $t$ test and the Mann-Whitney U test. Categorical variables were analyzed using the chi-square test. Spearman correlation analysis was performed to evaluate the correlation between NLR values and BCVA. Definition of the diagnostic value of NLR in the prediction of NAION was obtained by receiver operating characteristic (ROC) analysis. $\mathrm{p}<0.05$ was accepted as statistically significant.

\section{RESULTS}

Mean age was $60.1 \pm 11.8$ years in subjects with NAION and $62.7 \pm 12.1$ years in the control group $(p=0.29)$. There was no significant difference in gender distribution $(\mathrm{p}=0.54)$. Demographic data are shown in Table 1. In the control group, 9 subjects had DM, 6 subjects had hypertension, and 10 subjects 
had both DM and hypertension. In subjects with NAION, 8 subjects had DM, 7 subjects had hypertension, and 10 subjects had both DM and hypertension. The distribution of systemic diseases did not show a significant change between control group and subjects with NAION ( $\mathrm{p}=0.136)$.

Laboratory data of the groups are summarized in Table 1. Mean numbers of WBC, neutrophil, NLR and platelet count were significantly higher in subjects with NAION compared to the control group $(\mathrm{p}<0.001, \mathrm{p}<0.001, \mathrm{p}=0.004, \mathrm{p}=0.037$, respectively). Numbers of monocytes and lymphocytes were also higher in subjects with NAION compared to the control group, but the difference was not significant $(p=0.067, p=0.41$,

TABLE 1. Demographic data and laboratory findings

\begin{tabular}{|c|c|c|c|}
\hline & $\begin{array}{c}\mathrm{NAION} \\
\text { mean } \pm \mathrm{SD} \\
\mathrm{n}=45\end{array}$ & $\begin{array}{c}\text { Control } \\
\text { mean } \pm \text { SD } \\
n=50\end{array}$ & $\mathrm{p}$ \\
\hline Age (years) & $60.1 \pm 11.8$ & $62.7 \pm 12.1$ & $0.29 *$ \\
\hline Gender $(\mathrm{M} / \mathrm{F})$ & $23 / 22$ & $25 / 25$ & $0.54 * *$ \\
\hline $\mathrm{WBC}\left(10^{3} / \mathrm{mm}^{3}\right)$ & $8.33 \pm 2.2$ & $6.81 \pm 1.5$ & $<0.001 *$ \\
\hline Neutrophil $\left(10^{3} / \mathrm{mm}^{3}\right)$ & $5.18 \pm 1.6$ & $3.91 \pm 1.1$ & $<0.001^{*}$ \\
\hline NLR & $2.44 \pm 1.0$ & $1.85 \pm 0.5$ & $0.004 * * *$ \\
\hline Platelet $\left(10^{3} / \mathrm{mm}^{3}\right)$ & $260.84 \pm 54.7$ & $236.54 \pm 54.5$ & $0.037 *$ \\
\hline Monocyte $\left(10^{3} / \mathrm{mm}^{3}\right)$ & $0.65 \pm 0.3$ & $0.51 \pm 0.2$ & $0.067 * * *$ \\
\hline Hemoglobin(g/dL) & $13.76 \pm 1.9$ & $14.25 \pm 1.3$ & $0.15^{*}$ \\
\hline Lymphocyte $\left(10^{3} / \mathrm{mm}^{3}\right)$ & $2.29 \pm 0.7$ & $2.18 \pm 0.6$ & $0.41 *$ \\
\hline
\end{tabular}

respectively). Hemoglobin value did not show a significant change between groups $(p=0.15)$. Laboratory findings in subgroups are given in Table 2. Numbers of WBC and neutrophils and NLR were significantly different between control group 1 (without any systemic disease) and subjects with NAION without any systemic disease $(\mathrm{p}=0.001, \mathrm{p}=0.001, \mathrm{p}=0.028$, respectively). The difference between control group 2 and subjects with NAION with DM and/or hypertension was not significant ( $p>0.05$ for all parameters).

NAION was bilateral in 4 subjects $(8.8 \%)$. The number of WBC was $8.17 . \pm 2.2 \times 10^{3} / \mathrm{mm}^{3}$, the number of lymphocytes was $2.27 \pm 0.7 \times 10^{3} / \mathrm{mm}^{3}$, the number of neutrophils was $5.07 \pm 1.6 \times 10^{3} / \mathrm{mm}^{3}$, NLR was $2.42 \pm 1.1$, the number of monocytes was $0.62 \pm 0.3 \times 10^{3} / \mathrm{mm}^{3}$ and the number of platelets was $264.7 \pm 55.7 \times 103 / \mathrm{mm}^{3}$ in unilateral NAION cases, whereas these figures were $9.96 . \pm 1.8 \times 10^{3} / \mathrm{mm}^{3}, 2.50 \pm 0.4 \times 10^{3} /$ $\mathrm{mm}^{3}, 6.27 \pm 1.7 \times 10^{3} / \mathrm{mm}^{3}, 2.60 \pm 0.9,1.01 \pm 0.6 \times 10^{3} / \mathrm{mm}^{3}$ and $221.00 \pm 16.8 \times 10^{3} / \mathrm{mm}^{3}$, respectively, in bilateral cases. Mean WBC, lymphocyte, neutrophil, NLR, monocyte and platelet values did not show any significant difference between unilateral and bilateral cases ( $p>0.05$ for all parameters).

Mean BCVA value of subjects with NAION was $0.21 \pm 0.26$ at the time of diagnosis. Mean NLR values were outlined in Table 3. NLR levels were found to be the highest in group 1. There was a negative correlation between initial NLR and initial BCVA in subjects with NAION ( $\mathrm{r}=-0.406, \mathrm{p}=0.008)$. Mean BCVA value was $0.38 \pm 0.35$ in the third month in subjects with NAION. A negative correlation between initial NLR and BCVA in the third month was observed $(\mathrm{r}=-408, \mathrm{p}=0.028)$.

TABLE 2. Laboratory findings in patients with and without associated systemic diseases

\begin{tabular}{|c|c|c|c|c|}
\hline & & $\begin{array}{c}\text { NAION } \\
\text { mean } \pm \text { SD }\end{array}$ & $\begin{array}{c}\text { Control } \\
\text { mean } \pm \text { SD }\end{array}$ & $\mathrm{p}$ \\
\hline \multirow[t]{2}{*}{$\mathrm{WBC}\left(10^{3} / \mathrm{mm}^{3}\right)$} & DM and/or HT(+) & $8.21 \pm 2.3$ & $7.59 \pm 1.5$ & $0.304 *$ \\
\hline & DM and/or HT(-) & $8.49 \pm 1.8$ & $6.57 \pm 1.5$ & $0.001 *$ \\
\hline \multirow[t]{2}{*}{ Neutrophil $\left(10^{3} / \mathrm{mm}^{3}\right)$} & DM and/or HT(+) & $5.14 \pm 1.5$ & $4.46 \pm 0.8$ & $0.078^{*}$ \\
\hline & DM and/or HT(-) & $5.27 \pm 1.4$ & $3.82 \pm 1.1$ & $0.001 *$ \\
\hline \multirow[t]{2}{*}{ NLR } & DM and/or HT(+) & $2.56 \pm 1.1$ & $2.07 \pm 0.6$ & $0.205^{* *}$ \\
\hline & DM and/or HT(-) & $2.37 \pm 0.8$ & $1.84 \pm 0.5$ & $0.028 * *$ \\
\hline \multirow[t]{2}{*}{ Platelet $\left(10^{3} / \mathrm{mm}^{3}\right)$} & DM and/or HT(+) & $262.59 \pm 58.4$ & $255.76 \pm 65.1$ & $0.701 * *$ \\
\hline & DM and/or HT(-) & $252.39 \pm 52.2$ & $233.40 \pm 39.4$ & $0.182^{*}$ \\
\hline \multirow[t]{2}{*}{ Monocyte $\left(10^{3} / \mathrm{mm}^{3}\right)$} & DM and/or HT(+) & $0.65 \pm 0.3$ & $0.57 \pm 0.2$ & $0.330^{*}$ \\
\hline & DM and/or HT(-) & $0.66 \pm 0.3$ & $0.49 \pm 0.1$ & $0.257 * *$ \\
\hline \multirow[t]{2}{*}{ Hemoglobin (g/dL) } & $\mathrm{DM}$ and/or HT(+) & $13.41 \pm 2.0$ & $13.51 \pm 1.4$ & $0.838^{*}$ \\
\hline & DM and/or HT(-) & $14.42 \pm 1.6$ & $14.15 \pm 1.4$ & $0.569^{*}$ \\
\hline \multirow[t]{2}{*}{ Lymphocyte $\left(10^{3} / \mathrm{mm}^{3}\right)$} & DM and/or HT(+) & $2.22 \pm 0.8$ & $2.31 \pm 0.7$ & $0.700^{*}$ \\
\hline & DM and/or HT(-) & $2.33 \pm 0.5$ & $2.11 \pm 0.5$ & $0.175^{*}$ \\
\hline
\end{tabular}

NAION: non-arteritic anterior ischemic optic neuropathy; WBC: white blood cell; NLR: neutrophil-to-lymphocyte ratio; DM: diabetes mellitus; HT: hypertension; SD: standard deviation; $\mathrm{p}$ : *independent samples t-test; **Mann-Whitney U test 
TABLE 3. NLR in groups according to initial BCVA

\begin{tabular}{lccc}
\hline & & \multicolumn{2}{c}{ NLR } \\
\cline { 3 - 4 } Group (BCVA) & $\mathrm{n}=45$ & mean \pm SD & Min-Max \\
\hline Group 1 $(\leq 0.03)$ & 12 & $3.13 \pm 1.04$ & $1.65-5.18$ \\
Group 2 $(0.05-0.1)$ & 14 & $2.30 \pm 0.97$ & $1.32-4.39$ \\
Group 3 $(0.2-0.4)$ & 9 & $2.02 \pm 0.56$ & $1.54-3.03$ \\
Group 4 ( $\geq 0.5)$ & 10 & $2.11 \pm 0.56$ & $1.34-2.75$ \\
\hline
\end{tabular}

NLR: neutrophil-to-lymphocyte ratio; BCVA: best corrected visual acuity; SD: standard deviation

ROC curve analyses suggested that the optimum NLR cutoff point for NAION was 1.94 with a sensitivity of $60 \%$ and a specificity of $63 \%$.

\section{DISCUSSION}

White blood cell count and its subtypes have been shown to be inflammatory markers which play an important role in predicting cardiovascular diseases (19). In patients with ST-elevation myocardial infarction, an increase in neutrophil count is associated with short-term prognosis and impaired microvascular perfusion. Neutrophils are mediators in the inflammatory response after acute myocardial infarction (20). Woo et al. (21) reported that an elevated neutrophil count was associated with the presence and severity of diabetic retinopathy as well as diabetes and concluded that neutrophil-mediated inflammation could play an important role in the pathogenesis of diabetic retinopathy.

The neutrophil-to-lymphocyte ratio can simply be calculated by dividing the peripheral neutrophil count by the lymphocyte count. As NLR combines two independent inflammatory markers, it is more useful than other leukocyte parameters because of its stability compared with other parameters that may be affected by different pathological, physiological and physical factors. Therefore, NLR is a more stable and reliable parameter compared to WBC and lymphocytes $(22,23)$. NLR is evaluated and considered an important inflammatory marker in a number of cardiac and non-cardiac diseases $(15,22)$. Gibson et al. (23) showed that NLR was a powerful predictor of mortality after coronary artery by-pass grafting. Recently, Ulu et al. (24) evaluated NLR in subjects with diabetic retinopathy and reported that NLR was higher in these subjects compared to normal subjects. They also concluded that NLR was correlated with the stage of diabetic retinopathy, so the severity of diabetic retinopathy was related with the level of inflammation.

In our study, we found that NLR was significantly higher in subjects with NAION compared to the control group and that it was negatively correlated with BCVA at the initial and third month examination. The sensitivity was $60 \%$ and the specificity of NLR in the diagnosis of NAION was $63 \%$ with a cut-off value of 1.94 . Since the sensitivity and specificity of the cut-off value of NLR in the diagnosis of NAION was determined somewhat lower in this study, the detected cutoff value may not be helpful in the diagnosis of NAION in clinical practice. The sensitivity and specificity of NLR in the diagnosis of NAION with optimum cut-off values should be evaluated in larger series. The difference in NLR was significant between the control group without any systemic disease and NAION patients without any systemic disease. Although NLR was higher in NAION patients with DM and/or hypertension compared to the control group with DM and/or hypertension, the difference was not significant. It is known that low grade inflammation plays a role in the pathogenesis of DM and hypertension which might have affected NLR. Imtiaz et al. (25) showed that NLR was significantly higher in subjects with DM and hypertension compared to the normal population. It has been reported that NLR can be affected in subjects with systemic diseases other than DM or hypertension, like pulmonary hypertension or obstructive sleep apnea syndrome and psoriasis (26-28). One drawback of our study is that we could not evaluate the existence of other systemic diseases as our study was retrospective. Another drawback is the limited number of patients included in our study. It is possible that other systemic diseases which can affect NLR but were not recorded in our subjects may play a role in the etiopathogenesis of NAION. In our opinion, all systemic diseases that are known to affect NLR should be evaluated in patients diagnosed as NAION.

The pathogenesis of NAION is not well known. It is believed to be a multifactorial disease where different combinations of some local and systemic risk factors play a role in the development of NAION (3). As NAION is not lethal, obtaining fresh newly affected tissue for histopathological evaluation is very difficult (16). Bernstein et al. (16) evaluated optic nerve changes in primate NAION models where capillary vascular thrombosis was induced by laser light and showed that early post-infarct events revealed inflammatory response and suggested that modulation of inflammation might be useful in the treatment of NAION. Early cellular inflammation plays an important role in NAION (17). Histopathological examination of the optic nerve from a 70 year-old man diagnosed with NAION 20 days before death because of renal failure, pancreatitis and hypercalcemia at 12 hours postmortem revealed infarct with surrounding inflammation (29).

To the best of our knowledge, there has been no study evaluating the relationship between NAION and NLR or WBC in the literature. Our study is the first to show that neutrophil-mediated inflammation WBC indices are important 
in the etiopathogenesis of NAION. In our study, NLR, WBC and neutrophil count was significantly higher compared to the control group, which supports a neutrophil-mediated inflammatory reaction in NAION. Besides, we have found that BCVA at the time of diagnosis and in the third month was significantly and negatively correlated with NLR. NLR was higher in subjects with lower BCVA at the time of diagnosis. Although this result did make us think that NLR might be correlated with the severity of inflammatory reaction, as our study was retrospective and we do not routinely perform laboratory evaluation at month 3 in our clinic, we could not evaluate NLR at month 3 of follow-up. Therefore, we cannot say that NLR can be used as a predictive factor, but we can say that NLR can be used as a marker in the diagnosis of NAION.

As a result, inflammatory reaction beside ischemic changes may play a role in the etiopathogenesis of NAION. Inflammatory mediators such as white cells, neutrophils and NLR may be used as a marker of NAION. Further prospective studies are needed to evaluate NLR as a predictor for the assessment of visual acuity and prognosis in NAION. If NLR can be used as a predictive factor in NAION, the diagnosis of atypical cases of NAION can be achieved more easily and the visual prognosis of these subjects can be predicted.

Ethics Committee Approval: Ethics committee approval was received for this study from the ethics committee of Afyon Kocatepe University Faculty of Medicine.

\section{Informed Consent: N/A.}

Peer-review: Externally peer-reviewed.

Author contributions: Concept - O.P., G.F.Y; Design - O.P., G.F.Y., S.İ.; Supervision - S.İ., Ü.Ü.İ.; Resource - O.P., G.F.Y., Ü.Ü.İ.; Materials - G.F.Y., S.İ.; Data Collection \&/or Processing O.P., S.İ.; Analysis \&/or Interpretation - G.F.Y., Ü.Ü.İ.; Literature Search - S.İ., Ü.Ü.İ.; Writing - O.P., G.F.Y.; Critical Reviews - O.P., G.F.Y., Ü.Ü.İ.

Conflict of Interest: No conflict of interest was declared by the authors.

Financial Disclosure: The authors declared that this study has received no financial support.

\section{REFERENCES}

1. Hayreh SS, Joos KM, Podhajsky PA, Long CR. Systemic diseases associated with nonarteritic anterior ischemic optic neuropathy. Am J Ophthalmol 1994;118:766-80. [CrossRef]
2. Johnson LN, Arnold AC. Incidence of nonarteritic and arteritic anterior ischemic optic neuropathy. Population based study in the state of Missouri and Los Angeles County, California. J Neuroophthalmol 1994;14:38-44. [CrossRef]

3. Hayreh SS. Ischemic optic neuropathies - where are we now?. Graefes Arch Clin Exp Ophthalmol 2013;251:1873-84. [CrossRef]

4. Arnold AC. Pathogenesis of nonarteritic anterior ischemic optic neuropathy. J Neuroophthalmol 2003;23:157-63. [CrossRef]

5. McCulley TJ, Lam BL, Feuer WJ. A comparison of risk factors for postoperative and spontaneous nonarteritic anterior ischemic optic neuropathy. J Neuroophthalmol 2005;25:22-4. [CrossRef]

6. Buck BH, Liebeskind DS, Saver JL, Bang OY, Yun SW, Starkman $\mathrm{S}$, et al. Early neutrophilia is associated with volume of ischemic tissue in acute stroke. Stroke 2008;39:355-60. [CrossRef]

7. Haumer M, Amighi J, Exner M, Mlekusch W, Sabeti S, Schlager $\mathrm{O}$, et al. Association of neutrophils and future cardiovascular events in patients with peripheral artery disease. J Vasc Surg 2005;41:610-7. [CrossRef]

8. Stewart GJ. Neutrophils and deep venous thrombosis. Haemostasis 1993;23:127-40. [CrossRef]

9. Pitsavos C, Tampourlou M, Panagiotakos DB, Skoumas Y, Chrysohoou C, Nomikos T, et al. Association Between LowGrade Systemic Inflammation and Type 2 Diabetes Mellitus Among Men and Women from the ATTICA Study. Rev Diabet Stud 2007;4:98-104. [CrossRef]

10. Nakanishi N, Sato M, Shirai K, Suzuki K, Tatara K. White blood cell count as a risk factor for hypertension; a study of Japanese male office workers. J Hypertens 2002;20:851-7. [CrossRef]

11. Marsland AL, McCaffery JM, Muldoon MF, Manuck SB. Systemic inflammation and the metabolic syndrome among middle-aged community volunteers. Metabolism 2010;59:1801-8. [CrossRef]

12. Brooks GC, Blaha MJ, Blumenthal RS. Relation of C-reactive protein to abdominal adiposity. Am J Cardiol 2010;106:56-61. [CrossRef]

13. Rudiger A, Burckhardt OA, Harpes P, Muller SA, Follath F. The relative lymphocyte count on hospital admission is a risk factor for long-term mortality in patients with acute heart failure. Am J Emerg Med 2006;24:451-4. [CrossRef]

14. Tamhane UU, Aneja S, Montgomery D, Rogers EK, Eagle KA, Gurm HS. Association between admission neutrophil to lymphocyte ratio and outcomes in patients with acute coronary syndrome. Am J Cardiol 2008;102:653-7. [CrossRef]

15. Walsh SR, Cook EJ, Goulder F, Justin TA, Keeling NJ. Neutrophil-lymphocyte ratio as a prognostic factor in colorectal cancer. J Surg Oncol 2005;91:181-4. [CrossRef]

16. Bernstein SL, Johnson MA, Miller NR. Nonarteritic anterior ischemic optic neuropathy (NAION) and its experimental models. Prog Retin Eye Res 2011;30:167-87. [CrossRef]

17. Salgado C, Vilson F, Miller NR, Bernstein SL. Cellular inflammation in nonarteritic anterior ischemic optic neuropathy and its primate model. Arch Ophthalmol 2011;129:1583-91. [CrossRef] 
18. Hayreh SS, Jonas JB, Zimmerman MB. Nonarteritic anterior ischemic optic neuropathy and tobacco smoking. Ophthalmology 2007;114:804-9. [CrossRef]

19. Horne BD, Anderson JL, John JM, Weaver A, Bair TL, Jensen $\mathrm{KR}$, et al; Intermountain Heart Collaborative Study Group. Which white blood cell subtypes predict increased cardiovascular risk? J Am Coll Cardiol 2005;45:1638-43. [CrossRef]

20. Kirtane AJ, Bui A, Murphy SA, Barron HV, Gibson CM. Association of peripheral neutrophilia with adverse angiographic outcomes in ST-elevation myocardial infarction. Am J Cardiol 2004;93:532-6. [CrossRef]

21. Woo SJ, Ahn SJ, Ahn J, Park KH, Lee K. Elevated systemic neutrophil count in diabetic retinopathy and diabetes: a hospitalbased cross-sectional study of 30,793 Korean subjects. Invest Ophthalmol Vis Sci 2011;52:7697-703. [CrossRef]

22. Núñez J, Núñez E, Bodí V, Sanchis J, Miñana G, Mainar L, et al. Usefulness of the neutrophil to lymphocyte ratio in predicting long-term mortality in ST segment elevation myocardial infarction. Am J Cardiol 2008;101:747-52. [CrossRef]

23. Gibson PH, Croal BL, Cuthbertson BH, Small GR, Ifezulike AI, Gibson G, et al. Preoperative neutrophil-lymphocyte ratio and outcome from coronary artery bypass grafting. Am Heart $J$ 2007;154:995-1002. [CrossRef]
24. Ulu SM, Dogan M, Ahsen A, Altug A, Demir K, Acartürk $\mathrm{G}$, et al. Neutrophil-to Lymphocyte Ratio as a Quick and Reliable Predictive Marker to Diagnose the Severity of Diabetic Retinopathy. Diabetes Technol Ther 2013;15:942-7. [CrossRef]

25. Imtiaz F, Shafique K, Mirza SS, Ayoob Z, Vart P, Rao S. Neutrophil lymphocyte ratio as a measure of systemic inflammation in prevalent chronic diseases in Asian population. Int Arch Med 2012;5:2. [CrossRef]

26. Yıldız A, Kaya H, Ertaş F, Oylumlu M, Bilik MZ, Yüksel M et al. Association between neutrophil to lymphocyte ratio and pulmonary arterial hypertension. Turk Kardiyol Dern Ars 2013;41:604-9. [CrossRef]

27. Sen BB, Rifaioglu EN, Ekiz O, Inan MU, Sen T, Sen N. Neutrophil to lymphocyte ratio as a measure of systemic inflammation in psoriasis. Cutan Ocul Toxicol 2014;33:223-7. [CrossRef]

28. Günay E, Sarınç Ulaşı I, Akar O, Ahsen A, Günay S, Koyuncu T, et al. Neutrophil-to-Lymphocyte Ratio in Chronic Obstructive Pulmonary Disease: A Retrospective Study. Inflammation 2014;37:374-80. [CrossRef]

29. Tesser RA, Niendorf ER, Levin LA. The morphology of an infarct in nonarteritic anterior ischemic optic neuropathy. Ophthalmology 2003;110:2031-5. [CrossRef] 